\title{
Minithoracotomy for mitral valve repair improves inpatient and postdischarge economic savings
}

\author{
Eugene A. Grossi, MD, ${ }^{a}$ Scott Goldman, MD, ${ }^{b}$ J. Alan Wolfe, MD, ${ }^{c}$ John Mehall, MD, ${ }^{d}$ \\ J. Michael Smith, MD, ${ }^{e}$ Gorav Ailawadi, MD, ${ }^{f}$ Arash Salemi, MD, ${ }^{\mathrm{g}}$ Matt Moore, MHA, ${ }^{\mathrm{h}}$ \\ Alison Ward, MD, ${ }^{a}$ and Candace Gunnarsson, EdD, ${ }^{i}$ presented on behalf of the Economic Workgroup \\ on Valvular Surgery
}

\begin{abstract}
Objective: Small series of thoracotomy for mitral valve repair have demonstrated clinical benefit. This multiinstitutional administrative database analysis compares outcomes of thoracotomy and sternotomy approaches for mitral repair.
\end{abstract}

\begin{abstract}
Methods: The Premier database was queried from 2007 to 2011 for mitral repair hospitalizations. Premier contains billing, cost, and coding data from more than 600 US hospitals, totaling 25 million discharges. Thoracotomy and sternotomy approaches were identified through expert rules; robotics were excluded. Propensity matching on baseline characteristics was performed. Regression analysis of surgical approach on outcomes and costs was modeled.
\end{abstract}

\begin{abstract}
Results: Expert rule analysis positively identified thoracotomy in 847 and sternotomy in 566 . Propensity matching created 2 groups of 367 . Mortalities were similar (thoracotomy $1.1 \%$ vs sternotomy $1.9 \%$ ). Sepsis and other infections were significantly lower with thoracotomy ( $1.1 \%$ vs $4.4 \%)$. After adjustment for hospital differences, thoracotomy carried a $17.2 \%$ lower hospitalization cost $(-\$ 8289)$ with a 2 -day stay reduction. Readmission rates were significantly lower with thoracotomy $(26.2 \%$ vs $35.7 \%$ at 30 days and $31.6 \%$ vs $44.1 \%$ at 90 days). Thoracotomy was more common in southern and northeastern hospitals $(63 \%$ vs $37 \%$ and $64 \%$ vs $36 \%$, respectively), teaching hospitals (64\% vs 36\%) and larger hospitals ( $>600$ beds, $78 \%$ vs $22 \%$ ).
\end{abstract}

Conclusions: Relative to sternotomy, thoracotomy for mitral repairs provides similar mortality, less morbidity, fewer infections, shorter stay, and significant cost savings during primary admission. The markedly lower readmission rates for thoracotomy will translate into additional institutional cost savings when a penalty on hospitals begins under the Affordable Care Act's Hospital Readmissions Reduction Program. (J Thorac Cardiovasc Surg 2014;148:2818-22)

\section{Supplemental material is available online.}

In the 1990s, there was a resurgence of thoracotomy approaches for mitral valve repair with the goal of

From NYU Langone Medical Center, ${ }^{a}$ New York, NY; Main Line Health Care, Wynnewood, Pa; Northeast Georgia Medical Center, ${ }^{c}$ Gainesville, Ga; Penrose-St Francis Health Services, ${ }^{\mathrm{d}}$ Colorado Springs, Colo; TriHealth Heart Institute, ${ }^{\mathrm{e}}$ Cincinnati, Ohio; University of Virginia, ${ }^{\mathrm{f}}$ Charlottesville, Va; New York PresbyterianWeill Cornell Medical Center, ${ }^{\mathrm{g}}$ New York, NY; Edwards Lifesciences LLC, Irvine, Calif; and S2 Statistical Solutions, Inc, ${ }^{\mathrm{i}}$ Cincinnati, Ohio.

Funding for this project was provided by Edwards Lifesciences LLC, Irvine, Calif. This included funding for access to the Premier database and statistical analysis.

Disclosures: Matt Moore is employed by Edwards Lifesciences LLC, Irvine, Calif.

Candace Gunnarsson is employed by CTI Clinical Trial and Consulting Services,

Cincinnati, Ohio. All other authors have nothing to disclose with regard to commercial support

Read at the 94th Annual Meeting of The American Association for Thoracic Surgery, Toronto, Ontario, Canada, April 26-30, 2014.

Received for publication April 8, 2014; revisions received Aug 2, 2014; accepted for publication Aug 18, 2014; available ahead of print Sept 16, 2014.

Address for reprints: Eugene A. Grossi, MD, NYU Langone Medical Center, 530

First Ave, Suite 9V, New York, NY (E-mail: eugene.grossi@nyumc.org).

$0022-5223 / \$ 36.00$

Copyright (c) 2014 by The American Association for Thoracic Surgery

http://dx.doi.org/10.1016/j.jtcvs.2014.08.029 translating the successes of laparoscopic surgery into the field of limited-access mitral surgery. ${ }^{1-4}$ Several champions and institutional series have shown differential benefits of this approach relative to sternotomy; these benefits include reductions in cost, hospital stay, and blood transfusions. with an overall faster recovery. ${ }^{5-13}$ Unfortunately, these studies have been limited by small size or lack of financial and long-term outcomes. To provide greater insight into the hospital costs associated with minimally invasive mitral surgery, a group of experienced minimally invasive cardiac surgeons (Economic Workgroup on Valvular Surgery; Table E1) examined a cross-section of United States hospital billing and coding data related to isolated mitral valve repair (IsoMVRep). The purpose of this study was to analyze the real-world clinical and economic outcomes of thoracotomy compared with those of sternal approaches for IsoMVRep.

\section{MATERIALS AND METHODS Data Source}

The Premier database is extensively used for economic analyses, including those of cardiothoracic surgery. ${ }^{14-18}$ It contains, with patient identifying data removed, complete patient billing, hospital cost, and coding histories from more than 600 US health care facilities. ${ }^{19}$ This study 


\section{Abbreviations and Acronyms \\ ICD-9=International Classification of \\ Diseases, Ninth Edition \\ IsoMVRep $=$ isolated mitral valve repair}

extracted data from more than 25 million inpatient discharges. An institutional review board waiver of informed consent was obtained from the New England Institutional Review Board, and an exemption was obtained (NEIRB 13-203). Patients included those older than 18 years who underwent IsoMVRep through either a thoracotomy or sternotomy incision between 2007 and 2011. IsoMVRep was identified for visits having the primary International Classification of Diseases, Ninth Edition (ICD-9) procedure code classification of 35.12. Patients who underwent coronary artery bypass grafting in conjunction with IsoMVRep, underwent another concomitant valve operation, or underwent procedures utilizing robotic technology were excluded.

A set of expert rules were developed to text mine the charge master billing files of the Premier database to identify surgical approach as either thoracotomy or sternotomy (any type, including partial). Figure E1 displays these expert rules for procedure identification and attrition. For all eligible patients, elements describing adverse events, hospital cost, surgery time, hospital stay, and readmissions were obtained from the database. Cost analysis reflected the actual cost of the procedure to the hospital. The preoperative All Patient Refined Diagnosis-Related Groups severity level was used as an index of clinical comorbidity. The 3M All Patient Refined Diagnosis-Related Groups Classification System, a widely adopted proprietary risk-adjustment classification tool, uses information from routine claims data to produce valid and reliable severity measurement and riskadjustment scores. ${ }^{20}$ It is used to account for differences related to an individual's severity of illness or risk of mortality in large data sets. Comorbid conditions that might influence procedure selection or outcomes of interest, such as previous organ transplant, the presence of pulmonary disease, or diabetes mellitus, were obtained through ICD-9 diagnosis and procedure codes. Information on sociodemographic characteristics and health insurance status was also included, as were descriptors of the care setting, namely census region, urban or rural setting, teaching hospital status, and facility bed count. Adverse events were identified by ICD-9 codes and summed into categories (Table E2).

\section{Statistical Analyses}

The objective of this study was to use the Premier hospital database to compare clinical and economic outcomes among patients undergoing IsoMVRep through a thoracotomy versus any sternal approach. Outcomes of interest included adverse events, hospital costs, hospital stay, and readmission rates. Propensity scoring was used to create well-matched groups for comparison. Extensive details of the statistical methodology are contained in the Appendix E1.

\section{RESULTS}

Data analysis identified 6007 patients undergoing IsoMVRep. Expert rule analysis positively identified IsoMVRep by thoracotomy in 847 cases and by sternotomy in 566 cases. By means of propensity matching, 2 balanced groups of 367 patients were created (Table 1). Frequencies of comorbid conditions were equally distributed. Mortality was not statistically different between the 2 groups (1.1\% for thoracotomy approach vs $1.9 \%$ for any sternotomy approach). Important clinical outcomes are listed in
Table 2. Neurologic $(2.5 \%$ vs $2.2 \%)$, pulmonary $(39.5 \%$ vs $37.3 \%)$, and wound complications $(4.9 \%$ vs $6.5 \%)$ were not statistically different between the thoracotomy and sternotomy groups, respectively. Sepsis and other infections were significantly lower with a thoracotomy approach $(1.1 \%$ vs $4.4 \% ; P<.0065)$. A thoracotomy was more likely than a sternotomy to be performed in southern and northeastern hospitals $(63 \%$ vs $37 \%$ and $64 \%$ vs $36 \%$ respectively; $P<.0001$ ), teaching hospitals ( $64 \%$ vs $36 \%$; $P<.0001)$, and larger hospitals $(>600$ beds, $78 \%$ vs $22 \% ; P<.0001$; Table 3$)$. Table 4 lists expenditures by surgical approach, as broken into various cost centers. After adjustment for hospital differences, patients treated through a thoracotomy had a $17.2 \%$ lower average primary hospitalization cost ( $-\$ 8289)$. The mean stay with a thoracotomy approach was 7.94 days, versus 10.2 days with any sternotomy approach. Significantly, 30- and 90-day readmission rates were lower in the thoracotomy group $(26.2 \%$ vs $35.7 \% ; P<.0052$; and $31.6 \%$ vs $44.1 \% ; P<.0005$, respectively).

\section{DISCUSSION}

This study is a real-world analysis of IsoMVRep that draws its data from more than 600 diverse hospitals participating in the Premier database. These institutions have contributed their data, stripped of patient identifiers, for patient billing, hospital cost, and coding histories into a communal database to allow effective comparative cost analysis. With such geographic and demographic variations, we were able to note significant regional differences in greater use of thoracotomy for IsoMVRep in southern and northeastern, teaching, and larger hospitals. Although one could argue that larger hospitals and teaching hospitals have the necessary critical mass to support lesser invasive cardiac surgery, it is unknown why thoracotomies were performed in greater proportion in southern and northeastern geographic areas.

The overall mortality reported here for mitral repair $(1.49 \%)$ is similar to that reported in the Society of Thoracic Surgeons registry for the same period and reinforces the validity of this data set. As reported before, this large propensity-matched series confirmed that IsoMVRep through a thoracotomy carried comparable mortality and significantly decreased rates of sepsis and infection, hospital cost, and length of stay relative to sternotomy. These differences are in contrast to an earlier report by Suri and colleagues, ${ }^{21}$ which propensity matched and compared sternotomy versus port-access approaches for mitral repair. Although Suri and colleagues ${ }^{21}$ did demonstrate significant decreases in postoperative ventilatory support with portaccess procedures, there were no other differences in outcomes. It is unclear whether this difference was due to its comparison of 2 university series, as opposed to realworld data, or whether there was more discriminatory power in our multi-institutional analysis. 
TABLE 1. Demographic characteristics after matching of patients undergoing mitral repair

\begin{tabular}{|c|c|c|c|c|c|}
\hline \multirow[b]{2}{*}{ Category } & \multicolumn{2}{|c|}{ Thoracotomy } & \multicolumn{2}{|c|}{ Sternotomy } & \multirow[b]{2}{*}{$P$ value } \\
\hline & $\mathbf{N}$ & $\%$ & $\mathbf{N}$ & $\%$ & \\
\hline Total & 367 & 100 & 367 & 100 & \\
\hline Age (y) & & & & & .7155 \\
\hline$<30-60$ & 138 & 37.6 & 146 & 39.8 & \\
\hline $60-69$ & 106 & 28.9 & 97 & 26.4 & \\
\hline$\geq 70$ & 123 & 33.5 & 124 & 33.8 & \\
\hline Race or ethnicity & & & & & .2049 \\
\hline White & 279 & 76.0 & 263 & 71.7 & \\
\hline African American & 24 & 6.5 & 37 & 10.1 & \\
\hline Hispanic & 4 & 1.1 & 8 & 2.2 & \\
\hline Other & 60 & 16.4 & 59 & 16.1 & \\
\hline Sex & & & & & $>.9999$ \\
\hline Female & 161 & 43.9 & 161 & 43.9 & \\
\hline Male & 206 & 56.1 & 206 & 56.1 & \\
\hline Insurance & & & & & $>.9999$ \\
\hline Commercial & 12 & 3.3 & 12 & 3.3 & \\
\hline Medicare & 179 & 48.8 & 179 & 48.8 & \\
\hline Medicaid & 12 & 3.3 & 12 & 3.3 & \\
\hline Managed care & 147 & 40.1 & 147 & 40.1 & \\
\hline Other & 17 & 4.6 & 17 & 4.6 & \\
\hline Health status & & & & & .4919 \\
\hline $\begin{array}{c}\text { APR-DRG severity } \\
\text { level } 1 \text { or } 2\end{array}$ & 141 & 38.4 & 132 & 36.0 & \\
\hline $\begin{array}{c}\text { APR-DRG severity } \\
\text { level } 3 \text { or } 4\end{array}$ & 226 & 61.6 & 235 & 64.0 & \\
\hline
\end{tabular}

The current economic cost analysis also demonstrates significant savings with the thoracotomy approach, with a reduction in the average primary hospitalization cost of

TABLE 2. Adverse events of propensity-matched groups after mitral repair

\begin{tabular}{|c|c|c|c|c|c|}
\hline \multirow[b]{2}{*}{ Category } & \multicolumn{2}{|c|}{ Thoracotomy } & \multicolumn{2}{|c|}{ Sternotomy } & \multirow[b]{2}{*}{$P$ value } \\
\hline & $\mathbf{N}$ & $\%$ & $\mathbf{N}$ & $\%$ & \\
\hline Total & 367 & 100 & 367 & 100 & \\
\hline Neurologic complications* & 9 & 2.5 & 8 & 2.2 & .8062 \\
\hline $\begin{array}{l}\text { Total pulmonary complications } \\
\text { (infections plus } \\
\text { noninfections) } \dagger\end{array}$ & 145 & 39.5 & 137 & 37.3 & .5438 \\
\hline $\begin{array}{l}\text { Pulmonary complications } \\
\text { excluding infections }\end{array}$ & 126 & 34.3 & 105 & 28.6 & .0951 \\
\hline Total infections $\ddagger$ & 23 & 6.3 & 43 & 11.7 & .0099 \\
\hline Pulmonary infections $\S$ & 19 & 5.2 & 32 & 8.7 & .0591 \\
\hline Sepsis and other infections $\|$ & 4 & 1.1 & 16 & 4.4 & .0065 \\
\hline Wound complications $\llbracket$ & 18 & 4.9 & 24 & 6.5 & .3403 \\
\hline In-hospital deaths & 4 & 1.1 & 7 & 1.9 & .3621 \\
\hline \multicolumn{6}{|c|}{$\begin{array}{l}\text { *Ischemic stroke, hemorrhagic stroke, transient cerebral ischemic attack. †Acute } \\
\text { respiratory failure, pulmonary insufficiency, atelectasis or pulmonary collapse, pneu- } \\
\text { monia. } \ddagger \text { Pneumonia, sepsis, bacteremia or systemic inflammatory response syn- } \\
\text { drome, postoperative infection. §Pneumonia. } \| \text { Sepsis, bacteremia or systemic } \\
\text { inflammatory response syndrome, postoperative infection. } \uparrow \text { Hematoma, seroma, or } \\
\text { hemorrhage complicating a procedure; wound disruption or dehiscence. }\end{array}$} \\
\hline
\end{tabular}

TABLE 3. Hospital characteristics after matching

\begin{tabular}{|c|c|c|c|c|c|c|c|c|c|}
\hline \multirow[b]{3}{*}{ Category } & \multicolumn{4}{|c|}{ Thoracotomy } & \multicolumn{4}{|c|}{ Sternotomy } & \multirow[b]{3}{*}{$P$ value } \\
\hline & \multicolumn{2}{|c|}{$\begin{array}{c}\text { By } \\
\text { visits }\end{array}$} & \multicolumn{2}{|c|}{$\begin{array}{c}\text { By } \\
\text { hospital }\end{array}$} & \multicolumn{2}{|c|}{$\begin{array}{c}\text { By } \\
\text { visits }\end{array}$} & \multicolumn{2}{|c|}{$\begin{array}{c}\text { By } \\
\text { hospital }\end{array}$} & \\
\hline & $\mathbf{N}$ & $\%$ & $\mathbf{N}$ & $\%$ & $\mathbf{N}$ & $\%$ & $\mathbf{N}$ & $\%$ & \\
\hline Total & 367 & 100 & 39 & 100 & 367 & 100 & 52 & 100 & \\
\hline \multicolumn{10}{|l|}{ Census region } \\
\hline Northeast & 80 & 21.8 & 11 & 28.2 & 51 & 13.9 & 7 & 13.5 & $<.0001$ \\
\hline Midwest & 17 & 4.6 & 7 & 18.0 & 29 & 7.9 & 7 & 13.5 & \\
\hline South & 249 & 67.9 & 12 & 30.8 & 146 & 39.8 & 24 & 46.2 & \\
\hline West & 21 & 5.7 & 9 & 23.1 & 141 & 38.4 & 14 & 26.9 & \\
\hline \multicolumn{10}{|l|}{ Location } \\
\hline Urban & 363 & 98.9 & 37 & 94.9 & 350 & 95.4 & 46 & 88.5 & .0040 \\
\hline Not urban & 4 & 1.1 & 2 & 5.1 & 17 & 4.6 & 6 & 11.5 & \\
\hline \multicolumn{10}{|l|}{ Type } \\
\hline Teaching & 325 & 88.6 & 21 & 53.9 & 185 & 50.4 & 24 & 46.2 & $<.0001$ \\
\hline Nonteaching & 42 & 11.4 & 18 & 46.2 & 182 & 49.6 & 28 & 53.9 & \\
\hline \multicolumn{10}{|l|}{ Bed count } \\
\hline$<200$ & 3 & 0.8 & 2 & 5.1 & 6 & 1.6 & 1 & 1.9 & $<.0001$ \\
\hline $200-400$ & 22 & 6.0 & 13 & 33.3 & 122 & 33.2 & 22 & 42.3 & \\
\hline $401-600$ & 75 & 20.4 & 11 & 28.2 & 163 & 44.4 & 17 & 32.7 & \\
\hline$>600$ & 267 & 72.8 & 13 & 33.3 & 76 & 20.7 & 12 & 23.1 & \\
\hline
\end{tabular}

$\$ 8289(17.2 \%)$. Part of this savings is attributable to a 2-day reduction in hospital stay associated with a thoracotomy approach. In addition, as previously reported, ${ }^{10,22}$ blood use (as inferred from mean cost of $\$ 1122$ for thoracotomy vs $\$ 1671$ for sternotomy) was significantly reduced with a thoracotomy approach.

Although robotic mitral repairs were specifically excluded from this study, parallels between recent robotic economic studies and ours can be noted. Suri and associates ${ }^{23}$ recently reviewed the Mayo Clinic experience and concluded that robotics along with process improvement can be cost neutral, increasing "the affordability of new technologies capable of improving early patient outcomes." Likewise, Mihaljevic and colleagues ${ }^{24}$ performed propensity-based analyses of the economic cost of robotics for degenerative mitral repairs. They noted that after a threshold of 50 to 100 cases a year the cost of robotically assisted operations overlapped those of conventional approaches. As such, in exchange for higher procedural costs, robotic valve repair offered the clinical benefit of the least invasive surgery, the lowest postoperative cost, and the fastest return to work.

An important and interesting discovery in this analysis was the decreased readmission rates associated with the thoracotomy approach. At both 30 and 90 days, the thoracotomy cohort had significantly lower readmission rates. Although this difference was not calculated into the hospital cost saving presented here, it will certainly translate into further institutional cost savings as the Patient Protection and Affordable Care Act (Obama Care) penalty on hospitals begins under the Act's Hospital Readmissions Reduction Program. ${ }^{25}$ 
TABLE 4. Health care use and costs after matching

\begin{tabular}{|c|c|c|}
\hline & Thoracotomy & Sternotomy \\
\hline \multicolumn{3}{|c|}{ Total hospital costs } \\
\hline Median & $\$ 31,515$ & $\$ 37,495$ \\
\hline Mean & $\$ 37,156$ & $\$ 47,683$ \\
\hline $\mathrm{SD}$ & $\$ 19,624$ & $\$ 35,865$ \\
\hline \multicolumn{3}{|c|}{ Hospital costs by cost center } \\
\hline \multicolumn{3}{|c|}{ Blood bank } \\
\hline Median & $\$ 507$ & $\$ 799$ \\
\hline Mean & $\$ 1122$ & $\$ 1671$ \\
\hline $\mathrm{SD}$ & $\$ 2241$ & $\$ 2436$ \\
\hline \multicolumn{3}{|c|}{ Operating room } \\
\hline Median & $\$ 8886$ & $\$ 8029$ \\
\hline Mean & $\$ 9602$ & $\$ 8929$ \\
\hline SD & $\$ 4679$ & $\$ 5685$ \\
\hline \multicolumn{3}{|l|}{ Other } \\
\hline Median & $\$ 523$ & $\$ 246$ \\
\hline Mean & $\$ 3566$ & $\$ 1162$ \\
\hline $\mathrm{SD}$ & $\$ 4833$ & $\$ 3156$ \\
\hline \multicolumn{3}{|l|}{ Pharmacy } \\
\hline Median & $\$ 2078$ & $\$ 2232$ \\
\hline Mean & $\$ 2823$ & $\$ 4876$ \\
\hline $\mathrm{SD}$ & $\$ 2947$ & $\$ 15,211$ \\
\hline \multicolumn{3}{|l|}{ Radiology } \\
\hline Median & $\$ 438$ & $\$ 460$ \\
\hline Mean & $\$ 673$ & $\$ 807$ \\
\hline SD & $\$ 699$ & $\$ 1125$ \\
\hline \multicolumn{3}{|l|}{ Respiratory } \\
\hline Median & $\$ 688$ & $\$ 949$ \\
\hline Mean & $\$ 1226$ & $\$ 1664$ \\
\hline $\mathrm{SD}$ & $\$ 1788$ & $\$ 2417$ \\
\hline \multicolumn{3}{|c|}{ Room and board } \\
\hline Median & $\$ 5622$ & $\$ 9075$ \\
\hline Mean & $\$ 7372$ & $\$ 13,655$ \\
\hline $\mathrm{SD}$ & $\$ 9090$ & $\$ 17,226$ \\
\hline \multicolumn{3}{|c|}{ Intensive care unit } \\
\hline Median & $\$ 2662$ & $\$ 4177$ \\
\hline Mean & $\$ 4311$ & $\$ 8091$ \\
\hline $\mathrm{SD}$ & $\$ 7257$ & $\$ 15,073$ \\
\hline
\end{tabular}

\section{Limitations}

This study had some important limitations. This analysis was limited to a 90-day perioperative period, which limits any analyses related to potential long-term complications. Although thoracotomy approaches and partial sternotomy approaches are considered minimally invasive, data limitations did not allow for a distinction between and full and partial sternotomy approaches in this study. This large multi-institutional comparison of the sternal versus nonsternal approach for IsoMVRep, however, at the minimum shows the benefits of thoracotomy versus any sternal approach. These differences would be even greater if partial sternotomies were not included in the control group. ${ }^{26}$ In addition, although the total hospital costs are accurate, different institutions may have placed various items into different cost centers, and these differences may limit the usefulness of individual cost center analyses.

Finally, the arterial perfusion approach (antegrade or retrograde) was not available to analyze in this data set. The senior author (E.A.G.) has previously reported on both the changing incidence of arterial perfusion strategies and their differential outcomes. ${ }^{27}$ This study was designed to accurately test differences of surgical incision, however, not perfusion strategies. As such, our algorithm included the possibility of either femoral perfusion or central aortic perfusion.

\section{CONCLUSIONS}

Relative to sternal approaches, a thoracotomy approach for IsoMVRep provides similar mortality and less morbidity with fewer infections, shorter hospital stay, and significant cost savings during the primary admission. From an economic perspective, the markedly lower readmission rates associated with thoracotomy will translate into additional institutional cost savings when the Patient Protection and Affordable Care Act (Obama Care) penalty on hospitals begins with the Act's Hospital Readmissions Reduction Program.

\section{References}

1. Carpentier A, Loulmet D, Carpentier A, Le Bret E, Haugades B, Dassier P, et al. [Open heart operation under videosurgery and minithoracotomy. First case (mitral valvuloplasty) operated with success]. C R Acad Sci III. 1996;319: 219-23. French.

2. Grossi EA, LaPietra A, Ribakove GH, Delianides J, Esposito R, Culliford AT, et al. Minimally invasive versus sternotomy approaches for mitral reconstruction: comparison of intermediate-term results. J Thorac Cardiovasc Surg. 2001;121: 708-13.

3. Chitwood WR Jr, Wixon CL, Elbeery JR, Moran JF, Chapman WH, Lust RM. Video-assisted minimally invasive mitral valve surgery. J Thorac Cardiovasc Surg. 1997;114:773-80; discussion 80-2.

4. Mishra YK, Malhotra R, Mehta Y, Sharma KK, Kasliwal RR, Trehan N. Minimally invasive mitral valve surgery through right anterolateral minithoracotomy. Ann Thorac Surg. 1999;68:1520-4.

5. Grossi EA, Galloway AC, LaPietra A, Ribakove GH, Ursomanno P, Delianides J, et al. Minimally invasive mitral valve surgery: a 6-year experience with 714 patients. Ann Thorac Surg. 2002;74:660-3; discussion 663-4.

6. Galloway AC, Schwartz CF, Ribakove GH, Crooke GA, Gogoladze G, Ursomanno P, et al. A decade of minimally invasive mitral repair: long-term outcomes. Ann Thorac Surg. 2009;88:1180-4.

7. Gammie JS, Bartlett ST, Griffith BP. Small-incision mitral valve repair: safe, durable, and approaching perfection. Ann Surg. 2009;250:409-15.

8. Gammie JS, Zhao Y, Peterson ED, O'Brien SM, Rankin JS, Griffith BP. J. Maxwell Chamberlain Memorial Paper for adult cardiac surgery. Less-invasive mitral valve operations: trends and outcomes from the Society of Thoracic Surgeons Adult Cardiac Surgery Database. Ann Thorac Surg. 2010;90:1401-8. 1410 e1; discussion 1408-10.

9. D’Alfonso A, Capestro F, Zingaro C, Matteucci S, Rescigno G, Torracca L. Ten years' follow-up of single-surgeon minimally invasive reparative surgery for degenerative mitral valve disease. Innovations (Phila). 2012;7:270-3.

10. Goldstone AB, Atluri P, Szeto WY, Trubelja A, Howard JL, MacArthur JW Jr, et al. Minimally invasive approach provides at least equivalent results for surgical correction of mitral regurgitation: a propensity-matched comparison. J Thorac Cardiovasc Surg. 2013;145:748-56.

11. Aybek T, Dogan S, Risteski PS, Zierer A, Wittlinger T, Wimmer-Greinecker G, et al. Two hundred forty minimally invasive mitral operations through right minithoracotomy. Ann Thorac Surg. 2006;81:1618-24.

12. Vollroth M, Seeburger J, Garbade J, Pfannmueller B, Holzhey D, Misfeld M et al. Minimally invasive mitral valve surgery is a very safe procedure with 
very low rates of conversion to full sternotomy. Eur J Cardiothorac Surg. 2012; 42:e13-5; discussion e6.

13. Seeburger J, Borger MA, Falk V, Kuntze T, Czesla M, Walther T, et al. Minimal invasive mitral valve repair for mitral regurgitation: results of 1339 consecutive patients. Eur J Cardiothorac Surg. 2008;34:760-5.

14. Freeman RK, Dilts JR, Ascioti AJ, Dake M, Mahidhara RS. A comparison of length of stay, readmission rate, and facility reimbursement after lobectomy of the lung. Ann Thorac Surg. 2013;96:1740-5; discussion 1745-6.

15. Swanson SJ, Miller DL, McKenna RJ Jr, Howington J, Marshall MB, Yoo AC, et al. Comparing robot-assisted thoracic surgical lobectomy with conventional video-assisted thoracic surgical lobectomy and wedge resection: results from a multihospital database (Premier). J Thorac Cardiovasc Surg. 2014;147:929-37.

16. Swanson SJ, Meyers BF, Gunnarsson CL, Moore M, Howington JA, Maddaus MA, et al. Video-assisted thoracoscopic lobectomy is less costly and morbid than open lobectomy: a retrospective multiinstitutional database analysis. Ann Thorac Surg. 2012;93:1027-32.

17. Howington JA, Gunnarsson CL, Maddaus MA, McKenna RJ, Meyers BF, Miller D, et al. In-hospital clinical and economic consequences of pulmonary wedge resections for cancer using video-assisted thoracoscopic techniques vs traditional open resections: a retrospective database analysis. Chest. 2012;141:429-35.

18. Pasquali SK, Sun JL, d'Almada P, Jaquiss RD, Lodge AJ, Miller N, et al. Center variation in hospital costs for patients undergoing congenital heart surgery. Circ Cardiovasc Qual Outcomes. 2011;4:306-12.

19. Premier Professional Systems Inc. Huntsville, AL: Premier Professional Systems Inc; c2007-10. Available at: http://www.premier-inc.com/. Accessed December 2012.
20. Averill R, Goldfield N, Hughes J, Muldoon J, Gay J, McCullough E, et al. What are APR-DRGs? An introduction to severity of illness and risk of mortality adjustment methodology. Salt Lake City, UT: 3M Health Information Systems; 2003.

21. Suri RM, Schaff HV, Meyer SR, Hargrove WC III. Thoracoscopic versus open mitral valve repair: a propensity score analysis of early outcomes. Ann Thorac Surg. 2009;88:1185-90.

22. Cheng DC, Martin J, Lal A, Diegeler A, Folliguet TA, Nifong LW, et al. Minimally invasive versus conventional open mitral valve surgery: a meta-analysis and systematic review. Innovations (Phila). 2011;6:84-103.

23. Suri RM, Thompson JE, Burkhart HM, Huebner M, Borah BJ, Li Z, et al. Improving affordability through innovation in the surgical treatment of mitral valve disease. Mayo Clin Proc. 2013;88:1075-84.

24. Mihaljevic T, Koprivanac M, Kelava M, Goodman A, Jarrett C, Williams SJ, et al. Value of robotically assisted surgery for mitral valve disease. JAMA Surg. 2014; 149:679-86.

25. Patient Protection and Affordable Care Act Health-Related Portions of the Health Care and Education Reconciliation Act of 2010. Pub L No. 111-148, 124 Stat 119-1025.

26. Mihaljevic T, Cohn LH, Unic D, Aranki SF, Couper GS, Byrne JG. One thousand minimally invasive valve operations: early and late results. Ann Surg. 2004;240: 529-34; discussion 534

27. Grossi EA, Loulmet DF, Schwartz CF, Ursomanno P, Zias EA, Dellis SL, et al. Evolution of operative techniques and perfusion strategies for minimally invasive mitral valve repair. J Thorac Cardiovasc Surg. 2012;143(4 Suppl):S68-70 


\section{APPENDIX E1. DETAILED STATISTICAL STRATEGY AND METHODOLOGY}

From more than 25 million inpatient admissions in the Premier database, 6007 IsoMVRep procedures were identified. Next, the type of arterial cannulation (aortic, femoral, both, or unspecified) was determined. Of those patients who had femoral arterial cannulation or both femoral and aortic cannulation, we looked at whether a bone saw blade or bone wax was ever used as a determinant of sternotomy approach. These 847 patients-with femoral or combined arterial cannulation, no bone saw use, and no bone wax use-comprised the thoracotomy cohort.

A quasi-randomization method, called propensity scoring, was used to create groups of analyzable patients who were well matched. Propensity scores were assigned on the basis of likely predictors of the outcome of interest. Covariates on which to match were selected on the basis of their availability in the Premier database as well as their general acceptance as factors associated with the outcomes of interest.

The goal of this propensity-matching analysis was to find pairs of patients undergoing and not undergoing a thoracotomy for IsoMVRep who shared similar propensities for candidacy for the procedure on the basis of the matching variables. In addition, this analysis sought to maximize the number of matched patients while ensuring that cohorts were not significantly different with respect to relevant characteristics.

A statistical software (SAS Institute Inc, Cary, NC) macro from the Mayo Clinic was used; this macro used "nearest neighbor matching" on the estimated propensity scores to choose matches for the patients who underwent a thoracotomy procedure. ${ }^{26}$ Propensity scores were calculated for likelihood of thoracotomy procedures for each of the patients included in the analysis on the basis of a nonparsimonious multivariable logistic regression model. Patients undergoing a thoracotomy for IsoMVRep were then matched with patients undergoing any sternotomy for IsoMVRep with a 1:1 ratio exactly $($ caliper $=0)$ on their sex. They were simultaneously matched within \pm 5 years on age and within a value of 0.0001 on their propensity for undergoing a sternotomy for IsoMVRep. Patient characteristics (race or ethnicity, marital status, region, and insurance) and co-morbid conditions (severity index, angina, dysrhythmias, chronic obstructive pulmonary disease, depression, extensive aortic atherosclerosis, kidney disease, previous coronary angioplasty, myocardial infarction [acute or old], and other coronary artery disease) were adjusted in the propensity score model.

Once the matched pairs had been obtained, to assess the extent to which the propensity matching reduced confounders, the distribution of several variables before and after matching were compared among the patients in the cohorts, including age, sex, race or ethnicity, insurance type, health status, region, and comorbid conditions. Group comparisons were made with $\chi^{2}$ tests.

Because hospital costs have been found to be positively skewed, a generalized linear model with a gamma distribution and a log link function was used to adjust for differences in hospital characteristics (teaching vs nonteaching, urban vs rural, and bed count) and to calculate the corresponding least square means of overall cost for the hospital stay within each matched cohort. Adverse events (defined by $I C D$-9 coding in Table 2) were summarized in tables by cohort, with $P$ values for the differences in event rates calculated for each event category (neurologic, pulmonary, infection, and wound). Analyses were performed with SAS software (version 9.2). 


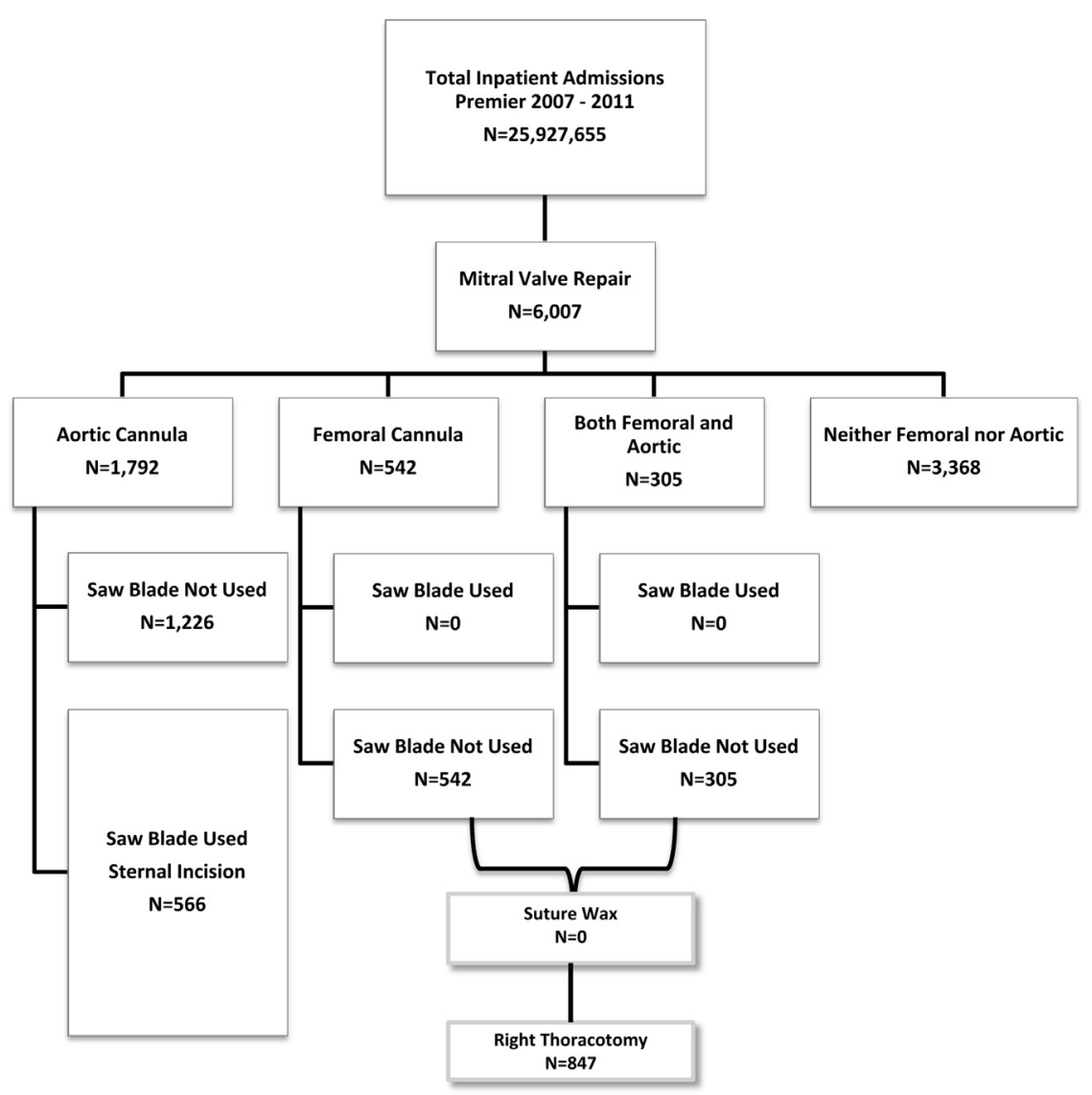

FIGURE E1. Flowchart demonstrating the expert rules used for procedure identification and attrition.

TABLE E1. Economic Workgroup on Valvular Surgery

\begin{tabular}{lll}
\hline \multicolumn{1}{c}{ Physician } & \multicolumn{1}{c}{ Hospital or group practice } & Location \\
\hline Gorav Ailawadi, MD & University of Virginia & Charlottesville, Va \\
Mark Anderson, MD & Einstein Medical Center & Philadelphia, Pa \\
Glenn Barnhart, MD & Swedish Medical Center & Seattle, Wash \\
Scott Goldman, MD & Main Line Cardiothoracic Surgery & Wynnewood, Pa \\
Eugene Grossi, MD & NYU Langone Medical Center & New York, NY \\
Clifton Lewis, MD & Princeton Baptist Medical Center & Birmingham, Ala \\
Michael Mack, MD & The Heart Hospital Baylor Plano & Dallas, Tex \\
Chris Malaisrie, MD & Northwestern Memorial Hospital & Chicago, Ill \\
John Mehall, MD & Penrose-St. Francis Health Services & Colorado Springs, Colo \\
Robert Riley, MD & Arizona Cardiovascular & Scottsdale, Ariz \\
Evelio Rodriguez, MD & Saint Thomas Heart & Nashville, Tenn \\
Eric Roselli, MD & Cleveland Clinic & Cleveland, Ohio \\
William Ryan, MD & The Heart Hospital Baylor Plano & Dallas, Tex \\
Arash Salemi, MD & New York Presbyterian-Weill Cornell Medical Center & New York, NY \\
J. Michael Smith, MD & TriHealth Heart Institute & Cincinnati, Ohio \\
J. Alan Wolfe, MD & Northeast Georgia Physicians Group & Atlanta, Ga \\
\hline
\end{tabular}


TABLE E2. Adverse events (International Classification of Diseases, Ninth Edition codes)

\begin{tabular}{|c|c|}
\hline Adverse events by category & ICD-9 codes \\
\hline \multicolumn{2}{|l|}{ Neurologic complications } \\
\hline Ischemic stroke & 433.x1, 434.x1, 997.02 \\
\hline Hemorrhagic stroke & $430,431,432 . x$ \\
\hline Transient cerebral ischemic attack & 435.x \\
\hline \multicolumn{2}{|l|}{ Pulmonary complications-infections } \\
\hline Pneumonia & $\begin{array}{l}\text { 480.x, 481, 482.x-484.x, 485, 486, 487, 490, 491.21, 491.22, 507.0, } \\
\quad 510.0,510.9,513,513.0,513.1,519.01,997.31,997.32\end{array}$ \\
\hline \multicolumn{2}{|l|}{ Pulmonary complications—noninfectious } \\
\hline Acute respiratory failure and pulmonary insufficiency & $518.81,518.84,518.5$ \\
\hline Atelectasis or pulmonary collapse & 518.0 \\
\hline \multicolumn{2}{|l|}{ Pulmonary complications-excluding infections } \\
\hline Lung complications noninfectious & $\begin{array}{l}511.0-511.1,511.89,511.9,512.0,512.1,514,518.4 \text {, and } 997.39 \\
\text { (if patient not already in another pulmonary category) }\end{array}$ \\
\hline \multicolumn{2}{|l|}{ Sepsis and other infections } \\
\hline Septicemia, bacteremia, or SIRS & 038.xx, 790.7, 995.9x \\
\hline Postoperative infection & $998.5 x, 999.0,999.3 x$ \\
\hline \multicolumn{2}{|l|}{ Wound complications } \\
\hline Hematoma, seroma, or hemorrhage complicating a procedure & $998.1 \mathrm{x}$ \\
\hline Wound disruption or dehiscence & $998.3 x$ \\
\hline \multicolumn{2}{|l|}{ Death } \\
\hline In-hospital death & From Premier data \\
\hline
\end{tabular}

